\title{
Os desafios da mulher frente a necessidade da realização do exame preventivo: uma visão panorâmica dos diferentes diagnósticos cervicais
}

\author{
The challenges of women facing the need for preventive examination: an overview of different \\ cervical diagnoses
}

Los desafíos de las mujeres que enfrentan la necesidad de un examen preventivo: una descripción general de los diferentes diagnósticos de cuello uterino

Tayane Christine Pereira Santana ORCID: https://orcid.org/0000-0002-3407-4038 Universidade Nilton Lins, Brasil E-mail: Tayanesantana092@gmail.com Alysson Bastos Sena ORCID: https://orcid.org/0000-0002-0562-8433 Universidade Nilton Lins, Brasil E-mail: alyssonsena@hotmail.com

\begin{abstract}
Resumo
O câncer de colo do útero é quarto tipo de câncer que mais acomete mulheres no mundo e tem forte correlação com a incidência do papiloma vírus humano (HPV), e apesar de existir um programa nacional de rastreio do mesmo no Sistema Único de Saúde a cobertura ideal desse tipo de serviço nunca foi atingida. Nesse contexto, há um aumento dos índices de subnotificação e acompanhamento das lesões precursoras de baixo grau que, ao falhar, deixa de prevenir casos que poderiam ser tratados antes de complicações. Este artigo discute três questões importantes nessa dinâmica: a) quais os fatores que levam a não realização do exame preventivo? b) Quais os métodos preventivos que impedem o contágio pelo vírus e suas eficácias? c) Quais os métodos de detecção da presença do HPV e de lesão precursora e quão eficientes estes são? Conclui-se que há coesão na literatura sobre os motivos que levam a não realização de exames preventivos, sendo eles de causas psicológicas, socioeconômicas e de conscientização. Há indícios de que os métodos preventivos tem sido avaliados para homens e mulheres, e são baseados no do uso de preservativos e na vacinação em massa de jovens contra o HPV. Ao final, os métodos de detecção disponíveis atualmente são capazes de diagnosticar a infecção específica presente no examinado, e quando esses métodos são utilizados em conjuntos específicos possibilitam a previsão do desenvolvimento maligno ou não inerente a cada caso.
\end{abstract}

Palavras-chave: Lesões de baixo grau; HPV; Lesões precursoras; Saúde pública.

\begin{abstract}
Cervical cancer is the fourth more common type of cancer to affect women worldwide existing a strong correlation of it with the incidence of human papillomavirus (HPV), and even with the existence of a national tracking program in the Unic Health System, the coverage of this service has never achieved its ideal rate. In this context, there is a growth of subnotifications and following-ups of lower grade precursor lesions that, in failing, stops preserving cases that could be treated before complications. This paper discusses three important questions related to this dynamic: a) what factors lead women not to do the preventive exams? b) What are the preventive methods that impede the contagion by the virus and what are their efficiencies? c) What detection methods for HPV presence and precursor lesions are available and are they efficient? It is concluded that there is an agreement between the bibliography that the most important reasons for not doing the preventive exams are of psychological, socioeconomic and of awareness. There is evidence that preventive methods are being thought to suit both men and women, and are mostly thought of by the use of condoms and mass HPV vaccination of the youth. Finishing, the detection methods available today are capable of diagnosing the specific infection present at the exam subject, and when different methods are used in different combinations, they enable the possibility of foreseeing the development of oncologic lesions or not in each specific case.
\end{abstract}

Keywords: Lower grade lesions; HPV; Precursor lesions; Public health.

\section{Resumen}

El cáncer de cuello uterino es el cuarto tipo de cáncer que más afecta a las mujeres en el mundo y tiene una fuerte correlación con la incidencia del virus del papiloma humano (VPH), y aunque existe un programa nacional de detección del mismo en el Sistema Único de Salud, la cobertura ideal de este tipo de servicio nunca se ha logrado. En este contexto, se observa un aumento de las tasas de subregistro y seguimiento de las lesiones precursoras de bajo grado que, al fallar, no logran prevenir casos que podrían tratarse antes de las complicaciones. En este artículo se analizan tres cuestiones 
importantes en esta dinámica: a) ¿Cuáles son los factores que llevan a no realizarse el examen preventivo? b) ¿Cuáles son los métodos preventivos que previenen el contagio del virus y su efectividad? c) ¿Cuáles son los métodos para detectar la presencia de VPH y lesiones precursoras y qué tan eficientes son? Se concluye que existe cohesión en la literatura sobre los motivos que llevan a no realizar exámenes preventivos, que son causas psicológicas, socioeconómicas y de sensibilización. Existe evidencia de que se han evaluado métodos preventivos tanto para hombres como para mujeres, y se basan en el uso de condones y la vacunación masiva de los jóvenes contra el VPH. Al final, los métodos de detección actualmente disponibles son capaces de diagnosticar la infección específica presente en el examinado, y cuando estos métodos se utilizan en conjuntos específicos, permiten predecir el desarrollo maligno o no inherente en cada caso.

Palabras clave: lesiones de bajo grado; VPH; Lesiones precursoras; Salud pública.

\section{Introdução}

O câncer de colo de útero é o quarto tipo de câncer que mais acomete mulheres em todo mundo. A necessidade de identificar lesões precursoras antes que se desenvolvam até tornarem-se o câncer é a forma mais utilizada de prevenção, já sendo uma realidade que os países desenvolvidos e com rastreamento eficaz realizam desde a primeira metade do século XX. O subrastreamento no Brasil, na região norte e, principalmente, no estado do Amazonas, contribui para carência de detecção do HPV e de identificação da lesão de baixo grau que poderia ser monitorada periodicamente.

A classificação atual das anormalidades citopatológicas é baseada no Sistema Bethesda: essa é a forma padrão para relatos da citologia cervical que foi aprovada após consenso de especialistas em 1988, atualizada em 2014, introduzindo os termos "lesões intraepiteliais escamosas de baixo grau" (LSIL, do inglês lowgrade squamous intraepithelial lesion) e "lesões intraepiteliais de alto grau" (HSIL, do inglês high-grade cervical squamous intraepithelial lesion), em substituição ao termo neoplasia intraepitelial cervical (NIC). Dessa forma, LSIL equivale ao antigo NIC1/infecção pelo HPV e HSIL equivale a NIC2 e NIC3. As atipias citológicas insuficientes para o diagnóstico de lesão intraepitelial são denominadas de "células escamosas atípicas" ou ASC e divididas em ASC-US (células escamosas atípicas de significado indeterminado, possivelmente nãoneoplásicas) e ASC-H (células escamosas atípicas não se podendo excluir lesão intraepitelial de alto grau) (Wright et al, 2012).

Esse artigo apresenta um quadro geral sobre o papiloma vírus humano (HPV) no Brasil e sua influência nos casos de câncer de útero. Para isso, discute quatro tópicos: a) identificar os fatores que levam a não realização do exame de Papanicolaou pela mulher; b) listar os métodos preventivos que impedem o contágio pelo vírus e discutir a eficiência dos mesmos; c) evidenciar os métodos de detecção da presença do HPV e de lesão precursora através da citologia clínica e testes moleculares. Através dos estudos que dialogam com essas questões, é possível demonstrar a importância da detecção do HPV e de lesões de baixo grau como parte fundamental do tratamento que impede a evolução das mesmas para o câncer de colo do útero.

\section{Metodologia}

A pesquisa tem base em uma revisão bibliográfica integrativa, possibilitando assim a busca, análise crítica e síntese do conhecimento produzido sobre o tema investigado podendo incluir estudos de diversas metodologias, empegando métodos definidos e claros para constatar criteriosamente pesquisas relativamente significativas, selecionar e avaliar criticamente pesquisas consideradas relevantes (Botelho et al, 2011). O reconhecimento do artigo é feito pesquisando as palavras-chave "HPV", "Câncer de colo do útero" e "Lesões de baixo grau” nas bases de dados LILACS, Pubmed e Ministério da Saúde. Foram selecionados artigos de pesquisas originais do ano de 2000 a 2020, que versem sobre o tema proposto em português, não sendo inclusos aqueles publicados em anos anteriores. Na seleção inicial foram selecionados 22 textos para análise, mas verificou-se que destes, 7 não estavam dentro do escopo do presente trabalho por não estarem dentro do recorte temporal ou dentro da temática trabalhada, sendo analisados ao final 15 artigos diferentes. 
Figura 1 - Seleção de literatura.

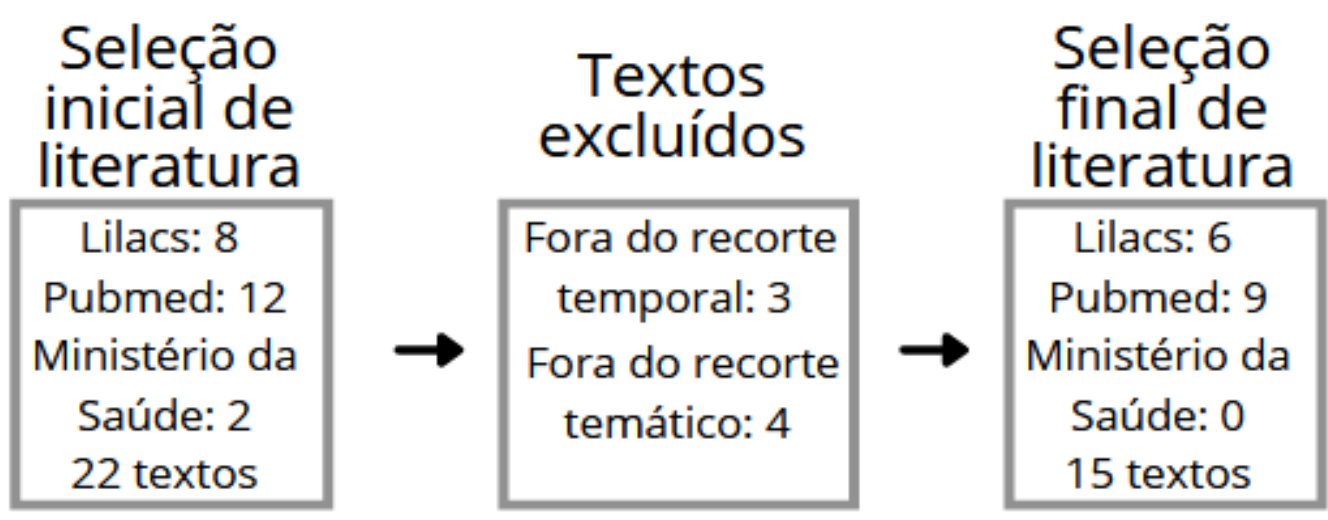

Fonte: Autores.

\section{Discussão e Resultados}

O papilomavírus humano (HPV) desempenha um papel central na carcinogênese cervical e em torno dele giram vários fatores que, direta ou indiretamente, influenciam a ocorrência ou não de alterações no epitélio escamoso cervical que podem evoluir para câncer. Entre os fatores mais estudados estão fatores imunológicos, tabagismo, idade, gravidez, uso de anticoncepcionais hormonais, cor e microbiota. Tudo isso, em maior ou menor grau, parece potencializar a ação do vírus nas células hospedeiras e facilitar a carcinogênese. O alto índice de regressão espontânea nos casos de infecção pelo HPV e o pequeno percentual que evolui para neoplasia invasiva, entretanto, sugerem que a infecção viral por si só não é suficiente e que outras variáveis estão envolvidas nesse processo (Pinto et al, 2012). Devido à alta taxa de mortalidade, esse estudo visa identificar fatores que impactam no quadro geral de saúde pública em relação ao câncer de colo de útero. Para tal, esse artigo apresenta quatro tópicos sobre diferentes questões com importância explicativa para atingir o objetivo principal: a) identificar os fatores que levam a não realização do exame de Papanicolaou pela mulher; b) listar os métodos preventivos que impedem o contágio pelo vírus e discutir a eficácia dos mesmos; c) evidenciar os métodos de detecção da presença do HPV e de lesão precursora através da citologia clínica e testes moleculares

A informação sobre a prevalência do HPV é mais frequentemente obtida no início da vida sexual do indivíduo, ou seja, durante a adolescência ou por volta dos 20 anos de idade. Esta infecção é passageira na maioria dos casos, sem manifestação clínica e pode curar-se espontaneamente. Existe uma variabilidade muito grande na incidência de infecção entre mulheres brancas e negras na mesma população, embora esse padrão pareça ter se tornado mais frequente nos últimos anos (Murta et al, 1999).

O programa de rastreio do SUS prevê o rastreio, porém não consegue uma cobertura ideal desse tipo de serviço e, consequentemente, há um aumento dos índices de subnotificação e acompanhamento das lesões precursoras. Esse cenário só pode ser agravado no estado do Amazonas, uma vez que se constata uma dificuldade específica no acesso aos serviços de saúde sobretudo devido às suas características geográficas. Estas impõem certo isolamento de municípios ribeirinhos, além de outros pontos que influenciam nessa questão como as cheias e vazantes dos rios, a disponibilidade de profissionais e de infraestrutura, esta última muitas vezes insuficiente nos serviços de saúde aos quais essa população tem acesso. Todos esses obstáculos reforçam a precariedade da Rede de Atenção à Saúde estadual (Oliveira et al, 2011; Garnelo et al, 2017).

Este artigo faz a análise de cinco textos que discutem as causas da evasão das pacientes dos exames preventivos (M. Oliveira et al, 2018; Camargos, 2013; Vasconcelos et al, 2020; Greenwood et al, 2006; Moura \& da Silva, 2017), sete artigos sobre os diferentes métodos preventivos ao HPV e ao câncer de colo de útero (Pinho, 2018; Nadal \& Manzione, 2006; Araujo et al, 2021; Viegas et al, 2019; Costa \& Goldenberg, 2013; Silva et al, 2021; Manoel et al, 2017) e três textos sobre a detecção do HPV e de lesões precursoras (Pogere, 2020; Adorno et al, 2020; Camargo, 2019). 
Foram obtidos os seguintes resultados: inicialmente, há coesão na literatura sobre os motivos que levam à não realização de exames preventivos por mulheres dentro das especificações recomendadas para fazê-los, sendo eles de causas psicológicas, socioeconômicas e de conscientização. Encontrou-se também indícios de que os métodos preventivos têm sido avaliados crescentemente para homens tanto quanto para mulheres, e são baseados no do uso de preservativos e na vacinação em massa de jovens e adolescentes contra a HPV. Ao final, os métodos de detecção disponíveis atualmente são capazes de diagnosticar precisamente a infecção presente na pessoa examinada, e quando esses métodos são utilizados em conjuntos específicos com as necessidades de cada caso possibilitam a previsão do desenvolvimento de cada caso permitindo melhor alocação de recursos da saúde.

Figura 2 - Resultados encontrados.

\section{Resultados}

\begin{tabular}{|c|c|c|}
\hline $\begin{array}{c}\text { Fatores de evasão } \\
\text { de exames } \\
\text { preventivos }\end{array}$ & $\begin{array}{l}\text { Métodos de } \\
\text { prevenção ao } \\
\text { contágio }\end{array}$ & $\begin{array}{c}\text { Prevenção contra o } \\
\text { câncer após } \\
\text { infecção }\end{array}$ \\
\hline $\begin{array}{c}\text { - Psicológicos } \\
\text { - Sócioeconômicos } \\
\text { - Conscientização }\end{array}$ & $\begin{array}{c}\text { - Rastreamento via } \\
\text { exames } \\
\text { - Vacinação em } \\
\text { massa }\end{array}$ & $\begin{array}{l}\text { - Tipagem do vírus } \\
\text { - Acompanhar a } \\
\text { evolução de lesões }\end{array}$ \\
\hline
\end{tabular}

Fonte: Autores.

\subsection{Evasão dos Exames Preventivos}

Segundo M. Oliveira et al (2018), o governo brasileiro almeja atingir uma taxa de cobertura de $85 \%$ da população feminina submetida ao exame citológico cervical, objetivo que não foi atingido. O artigo faz um levantamento referente aos dados obtidos no ano de 2013, e mostra que apenas 79,4\% das mulheres brasileiras fizeram o exame nos 3 anos anteriores à coleta dos dados, sendo que a região norte teve a segunda pior cobertura com apenas 75,5\%. Nas capitais a tendência era de maior amplitude com $82,3 \%$ de cobertura na população feminina local. Em relação aos anos estudados há outra grande disparidade: $93,6 \%$ das mulheres com ensino superior completo fizeram o exame, frente a 88,6\% das mulheres com 12 ou mais anos de estudo e 78,3\% de mulheres que tiveram de 0 a 8 anos de formação escolar e, além disso, em ambiente urbano a cobertura é de $80,1 \%$ em comparação a 74,1\% no meio rural. Essas informações são importantes para embasar estatisticamente a exposição de dados qualitativos que vêm à seguir.

A monografia de Camargos (2013) faz um bom trabalho de revisão bibliográfico nesse quesito: são quinze textos levantados e debatidos com diferentes perspectivas variadas sobre as causas da evasão feminina ao exame citológico cervical além dos trazidos pelo autor por sua experiência profissional clínica, embora alguns dos fatores estejam presentes em mais de um trabalho.

Um dos fatores que contribuem pela baixa adesão ao exame mais citados pela literatura mobilizada na monografia é a condição socioeconômica das mulheres que interfere na possibilidade de fazer o exame, sendo que o índice que mais evade o mesmo é de mulheres jovens, pobres, de baixa renda familiar e baixa escolaridade. Podemos citar diversas dificuldades de locomoção aos serviços de saúde tanto da zona urbana quanto rural, a dupla jornada feminina relativa ao trabalho no emprego 
formal e na vida doméstica e a impossibilidade de encontrar alguém para cuidar dos filhos durante o período do exame. Além disso, há a falta de instrução, fatores culturais, sociais e religiosos.

A taxa de cobertura anteriormente citada de apenas 78,3\% em mulheres pouco ou nada escolarizadas mostra-se enquanto dado na realidade com confusões sobre a finalidade do exame, confundindo o mesmo com exame de gravidez ou acreditando que por não serem sexualmente ativas, terem filhos ou algum sintoma de anormalidade estão imunes às patologias cervicais e não precisam fazer a prevenção. Há também diversas citações aos problemas referentes à burocratização do sistema de saúde, mostrando que a demora para consultas, para o atendimento e para o resultado da análise desestimula fortemente a adesão aos exames; isso aparece em dois dados interessantes: primeiramente, na cidade de São Paulo 56,8\% das mulheres fizeram seus exames preventivos em clínicas privadas e apenas $43,2 \%$ o fizeram em clínicas públicas, taxa semelhante a que se apresenta em Barbacena-MG, cidade de onde o autor fala, possibilitando não a inferência, mas a hipótese de que isso exprime uma generalizada insatisfação com o sistema público. Além disso, cita-se que algumas pacientes, queixando-se da demora para análise de suas coletas, buscam conseguir as lâminas para leva-las a laboratórios privados.

Outra categoria de desmotivadores é de fatores psicológicos e culturais: o medo do diagnóstico um fator que se reflete nas mulheres que apesar de terem sido coletadas deixam de buscar o resultado da análise por medo de uma possível neoplasia. Muitas mulheres relatam, também, sentir vergonha de fazer o exame, e embora esse fator seja citado singularmente na maior parte dos textos, há pistas na bibliografia sobre os fundos que alimentam esse sentimento: interpretam o exame como algo que tenha conotação sexual e não como um procedimento médico, as que não fazem o exame com médicos homens por proibição de seus maridos; e também fatores religiosos influenciam muito a decisão de realizar o exame. Por último, há relatos de diversas mulheres que dizem que sentiram-se desconfortáveis com a frieza do profissional que foi responsável pelo exame, sentindo estar em uma posição de subalternidade desumanizada, como apenas um objeto sendo analisado (Camargos, 2013).

Outros trabalhos confirmam as tendências apresentadas por Camargos (2013): Vasconcelos et al (2020), ao abordarem como mulheres acima de 45 anos desenvolvem câncer de colo de útero, citam a vergonha como um fator de alto impacto para a evasão dos exames preventivos; Greenwood et al (2006), ao abordarem os motivos pelos quais mulheres deixam de buscar os resultados de seus exames, atestam questões infraestruturais, como acesso a transporte, e socioeconômicos, como indisponibilidade de horários por conta do emprego ou não encontrar alguém que possa cuidar dos filhos, como impeditivos comuns; o trabalho de Moura e da Silva (2017) atestam todas essas questões tanto quanto a falta de conhecimento sobre a importância do exame e o atendimento público deficiente que desmotivam as mulheres a buscar fazê-lo. É possível compreender que existe um alto nível de consenso na literatura sobre quais os fatores que levam à evasão de exames preventivos, embora grande parte das soluções para essas questão fujam ao escopo dos trabalhadores da saúde e invadam o âmbito da administração pública e do sistema público de saúde.

\subsection{Métodos Preventivos}

O trabalho de Pinho (2018) faz uma revisão bibliográfica buscando analisar o custo-efetividade de procedimentos relativos ao HPV, discutindo o mesmo referente a imunização coletiva por meio da vacina quadrivalente (única disponibilizada pelo SUS - Sistema Único de Saúde) e do rastreio por meio do teste HPV e da citologia em meio líquido. As conclusões obtidas são de que dos 20 artigos analisados sobre o custo-efetividade das vacinas, apenas 2 dizem não valer a pena a imunização coletiva, embora essa conclusão em ambos os trabalhos seja motivada pelos custos do projeto e não pelo impacto na saúde e bem-estar da população vacinada; todos os 10 trabalhos analisados referentes ao teste de HPV são favoráveis quanto ao custoefetividade do mesmo para diagnosticar e rastrear infecções, permitindo diagnósticos e acompanhamentos antes que haja a possibilidade de complicações oncológicas; os estudos sobre o custo-efetividade da citologia em meio líquido são escassos e possuem conclusões divergentes: apenas 4 estudos foram encontrados sobre a temática, sendo que 2 concluíram que a economia 
inerente à maior precisão e aproveitamento de esfregaços faz da citologia em meio líquido viável enquanto outros 2 dizem a necessidade de compra e manutenção do equipamento, além da adequação de equipes para trabalharem com o processo, fazem dele inviável. Pinho (2018), portanto, parece expor como as tecnologias da saúde são desenvolvidas mas são impostas dificuldades na utilização das mesmas pela sociedade devido a problemas de distribuição de recursos, não de desconhecimento da técnica.

O trabalho de Nadal e Manzione (2006) além de atestar a eficiência da vacina na imunização coletiva, discutem como a decisão pela sua implementação tem impactos nos gastos públicos, uma vez que diminui drasticamente a necessidade de procedimentos complexos em relação às neoplasias e demais complicações oncológicas, muito mais custosos do que a vacinação, e impedem em grande proporção impactos emocionais nas pessoas que venham a adquirir o vírus e desenvolver quaisquer resultados anormais em seus corpos como efeito disso, argumento fundamentado no direito à dignidade humana inerente à saúde pública, perspectiva essa que é aprofundada no trabalho de Araújo et al (2021) sobre os efeitos biopsicossociais do HPV no indivíduo, com a carga de preconceito com pessoas infectadas e o preconceito internalizado pelo indivíduo afetado que pode impactar negativamente em sua autoestima.

Há de ser introduzido nesse raciocínio, contudo, um impeditivo presente na literatura e anteriormente citado, mas com produção focada no mesmo: a desinformação. Há a necessidade de introduzir na sociedade de formas melhor estruturadas as informações acerca do vírus HPV, seus efeitos na saúde e como prevenir a contaminação, como mostra Viegas et al (2019) em seu artigo sobre a cobertura vacinal ao HPV antes e depois da conscientização com jovens em idade escolar, quando a cobertura passa de $41 \%$ a $91 \%$. Nessa mesma linha, Costa e Goldenberg (2013) e Silva et al (2021) mostram como jovens deixam de ser vacinados por medo de agulhas, injeção e efeitos colaterais mesmo referentes a vacinas comprovadamente seguras e eficientes, muitas vezes com base em perspectiva proveniente da família.

Como não se esperaria, entretanto, esse trabalho precisa ser feito nos profissionais de saúde (Manoel et al, 2017), principalmente aqueles ligados à práticas de saúde da família e outras atividades focadas na comunidade para que estes possam repassar com segurança informações para a população atendida, o que é exposto como realizado até o presente momento de forma insatisfatória e insuficiente em diversos casos.

\subsection{Deteç̧ão da Presença do HPV e de Lesão Precursora}

Em seu trabalho, Pogere (2020) faz uma revisão sobre quatro métodos para o prognóstico de neoplasias intraepiteliais cervicais: citologia em meio líquido, colposcopia, citometria de imagem do conteúdo de DNA (DNA-ICM) e teste de HPV, tanto de alto risco quanto focado na variante tipo 16, controlando a qualidade de seus resultados com os resultados histopatológicos, visto que esse método é padrão ouro no diagnóstico de lesões de colo uterino.

Segundo a autora, a citologia oncótica teve uma taxa razoável de precisão detectando lesões de alto e baixo grau, com taxas de 67,9\% e 76,1\%, respectivamente, mas uma taxa baixa referente à detecção do câncer, com apenas 28,6\% dos casos encontrados. A colposcopia, por sua vez, detectou $70 \%$ das lesões de alto grau, $90 \%$ das lesões de baixo grau e $87,5 \%$ dos cânceres, excluindo desse cálculo os que não eram aparentes e, portanto, fora do escopo desse exame. O teste de DNA-ICM detectou 71,3\% das lesões de alto grau, 85,2\% das lesões de baixo grau e $100 \%$ dos cânceres. O teste de HPV foi feito em 46,9\% da amostra total por meio de análise de material recolhido por biópsia. Nesse segmento, o teste para variantes de alto risco detectou o vírus presente em $64,8 \%$ da amostra total, estando presente em $50 \%$ das lesões de baixo grau, 75,4\% das lesões de alto grau e 71,4\% dos casos de câncer, enquanto o teste para o tipo 16 detectou a presença da variante em 33,6\% das pacientes contaminadas pelo HPV na amostra, estando presente em 11,4\% das lesões de baixo grau, 40,4\% das de alto grau e71,4\% dos casos de câncer.

A partir das observações são extraídas as seguintes informações: 
Figura 3 - Sensibilidade e Especificidade de métodos diagnósticos.

\begin{tabular}{lcc}
\hline Método diagnóstico & $\begin{array}{l}\text { Sensibilidade } \\
\text { (IC 95\%) }\end{array}$ & $\begin{array}{l}\text { Especificidade } \\
\text { (IC 95\%) }\end{array}$ \\
\hline Citologia & $72,3 \%(63,9-79,4)$ & $76,1 \%(67,3-83,1)$ \\
Colposcopia & $79,3 \%(71,0-85,6)$ & $94,4 \%(88,3-97,4)$ \\
DNA-ICM & $74,6 \%(66,2-81,4)$ & $85,3 \%(77,4-90,7)$ \\
HPV de alto risco* & $75,0 \%(63,1-84,0)$ & $50,0 \%(35,8-64,1)$ \\
HPV 16 & $43,75 \%(32,2-55,9)$ & $88,64 \%(76,0-95,0)$ \\
& & \\
\hline
\end{tabular}

Fonte: Pogere (2020, p.79).

A autora cita, ao analisar os dados, que a citologia tem bom nível de associação em diagnósticos tanto de baixo quanto de alto grau, embora apenas $28,6 \%$ das suspeitas tenham sido confirmadas e 2 casos que normalmente não são preocupantes tiveram diagnóstico de câncer, confirmando as críticas sobre altas taxas de falsos negativos e baixa reprodutibilidade na intepretação, que teria alta possibilidade de ser interpretada de múltiplas formas por múltiplos profissionais.

A colposcopia, por sua vez, se mostra como o método mais eficiente dentro os utilizados e estudados no trabalho da autora, com uma alta taxa de especificidade e sensibilidade, o que permite que em aproximadamente $80 \%$ dos casos seja possível diferencias um colo lesionado de um saudável, tendo apenas a ressalva de que haveria "supervalorização somente em 6\% e, na maior parte dos 20,7\% subestimados, o diagnóstico era NIC 2, o que é consistente com a literatura que relata que, de fato, ela é menos sensível na detecção dessa categoria intermediária" (Pogere, 2020, p.99).

A autora termina sua exposição argumentando que os testes de DNA-ICM e os de HPV, tanto de alto risco quanto da variável 16, são melhor utilizados juntos, uma vez que, apoiada na literatura, percebe haver uma "maior eficiência no diagnóstico quando o resultado da DNA-ICM automatizada foi analisado em conjunto com o da testagem para HPV 16 e 18" (Pogere, 2020, p.99)

Em outra perspectiva, Adorno et al (2020) mostram que testar mulheres que tiveram diagnóstico de atipia de células escamosas para HPV's de alto risco, na verdade, pode permitir um acompanhamento mais cuidadoso e com maior precisão de lesões, tanto àquelas de baixo quanto de alto grau, enquanto diminui a necessidade de acompanhamento com exames mais complexos que a citologia em mulheres sem esse diagnóstico. Isso seria consequência da compreensão de que se a causa da atipia está diretamente vinculada à infecção por papiloma vírus humano, então os acompanhamentos precisam ter espaços menores de tempo entre si pois a possibilidade de surgirem lesões de baixo e alto grau sobem muito: apenas 5,5\% das pacientes negativadas no teste de HPV tiveram lesões de baixo grau enquanto, segundo o estudo, em um ano, 39\% das pacientes que testaram positivo para HPV tiveram novas lesões cervicais. A inferência de que o acompanhamento em mulheres sem infecção pelo vírus precisaria de um acompanhamento menos rigoroso está baseada no alto valor preditivo negativo $(98,7 \%)$ exposto pelo estudo.

Em suma, os autores dizem que utilizar a metodologia do HC2 para investigar a presença do DNA de HPV de alto risco tem um grande valor preditivo negativo enfaticamente para LIEBG (Lesões Intraepiteliais de Baixo Grau), embora também para LIEAG (Lesões Intraepiteliais de Alto Grau). "Isso pode ajudar a definir o acompanhamento das pacientes com CEA (Células Escamosas Atípicas) à colpocitologia e reduzir os custos associados à triagem em longo prazo para a possível redução no número de colposcopias e biópsias indicadas para essas pacientes" (Adorno et al, 2020, p.5). 
Em raciocínio semelhante, Camargo (2019) diz que o teste de DNA para HPV, sozinho, pode conseguir detectar as variantes envolvidas na infecção sob análise e ajudar a encaminhar a paciente para o tratamento adequado a seu quadro. Entretanto, ele não responde uma pergunta fundamental para o melhor encaminhamento o possível: qual o risco de progressão da lesão detectada? O exame molecular poderia, respondendo essa pergunta, diminuir a demanda por exames como a colposcopia e análise de biópsias, aliviando o sistema de saúde para dar espaço a pessoas que efetivamente precisassem desses procedimentos. "Na prática clínica o objetivo dos testes moleculares é identificar de maneira acurada e específica as mulheres que necessitam colposcopia por se tratarem de pacientes com risco mais elevado para HSIL" (Camargo, 2019, p.3).

A partir da bibliografia analisada, é possível compreender que existem múltiplos métodos eficientes, além de diferentes possibilidades de combinação entre os mesmos que maximiza a utilidade que tenham na construção de diagnósticos, para a detecção de lesões ou de suas causas, além do fato de que a melhor distribuição desses recursos pode causar impactos no sistema de saúde garantindo os exames específicos para diferentes quadros clínicos.

\section{Considerações Finais}

Esse artigo baseou-se sobre uma revisão bibliográfica, estando limitado por isso a analisar a produção científica selecionada, mas não agregando dados como os de um estudo original, embora traga análises relevantes para a área com os seguintes resultados: primeiramente, há um nível razoável de coesão na bibliografia acerca dos motivos que levam à não realização de exames preventivos pelas mulheres que deveriam fazê-los, sendo eles divisíveis em psicológicos, como medo do diagnóstico ou vergonha, socioeconômicos como dupla jornada de trabalho feminina e impossibilidade de usar meios de transporte, e de conscientização, como não saber qual a função dos exames preventivos ou porque fazê-los é tão importante.

Os métodos preventivos, por sua vez, têm sido baseados no rastreamento por meio de exames preventivos e o uso de vacinas para HPV que, para grande parte da literatura, tem um custo-efetividade notável e pode diminuir drasticamente as taxas de contaminação, o que resultaria numa notável queda de casos de câncer de colo de útero, dada a forte correlação entre o mesmo e o HPV.

As formas de detecção existentes são suficientes para diagnósticos completos, principalmente quando utilizados em conjuntos diferentes de acordo com as necessidades de cada caso, e possibilitam a previsão do desenvolvimento de cada caso, embora seja necessário uma melhor alocação de recursos pela administração da saúde baseada na literatura que mostra quais casos tem tendências muito maiores a desenvolver lesões e, das lesões desenvolver câncer, não sendo necessário exames complexos para todos os casos.

O que se apresenta é um cenário que possibilita dois grandes movimentos sobre a contenção do contágio pela HPV: inicialmente, é possível mitigar os danos que a infecção pode causar na saúde das mulheres por meio do exame preventivo, exame esse que acompanha o desenvolvimento de lesões de baixo grau que poderiam chegar ao nível oncótico. Por outro lado, a disponibilização das vacinas com cada vez maior amplitude permite pensarmos na possibilidade de que futuras gerações não precisarão conviver com as consequências das infecções por tipos agressivos do vírus; fazer dessa possibilidade uma realidade depende da boa condução de políticas públicas e do aprofundamento das pesquisas que são parte fundamental do esforço contra o HPV e o câncer de colo de útero.

Evidenciou-se que há novas possibilidades de melhor aplicação de recursos da saúde ligados ao acompanhamento de lesões de acordo com a tipagem do vírus, mudando a atual tendência da prática clínica de massificação dos exames preventivos, além de um futuro em que seja possível buscar a erradicação do HPV por meio de ampla vacinação. Mostrou-se também que diversas formas de não adesão aos programas de rastreio cervical para identificação de lesões precursoras e câncer cervical e a necessidade do desenvolvimento de estratégias que possam esclarecer a sociedade da grande importância deste diagnóstico que contribui para diminuição de casos de câncer de colo de útero. 


\section{Referências}

Adorno, F. A., Lousada, D. C. F., Coelho, K. M. P. A. \& França, P. H. C. F. (2020). A utilidade da captura híbrida para o HPV de alto risco em pacientes com atipia de células escamosas na colpocitologia. Jornal Brasileiro de Patologia e Medicina Laboratorial, 56, 1-6.

Araújo, L. N. C. C., Sousa, A. R., Tenório, E. N., Peixoto, K. A., Reis, S. O., Gashti, S. M., Oliveira, T. R. \& Barros, G. G. F. (2021). Impactos biopsicossociais do diagnóstico positivo de HPV nos portadores. Online: Revista Eletrônica Acervo Saúde, 13(5), 1-7.

Botelho, L. L. R., Cunha, C. C. A. \& Macedo, M. (2011). O método da revisão integrativa nos estudos organizacionais. Belo Horizonte: Gestão e Sociedade, 5(11), 121-136.

Camargo, A. C. M. (2019). Biologia Molecular na abordagem das alterações citológicas, lesões cervicais e na presença da infecção pelo HPV de alto risco. Associação Baiana de Patologia Cervical Uterina e Colposcopia. <http://sbpcuc.com.br/media/004Biologia_Molecu lar_na_abordagem_das_altera\%C3\%A7\%C3\%B5es_citol\%C3\%B3gicas,_les\%C3\%B5es_cervicais_e_na_presen\%C3\%A7a_da_infec\%C3\%A7\%C3\%A3o_p elo_HPV_de_alto_risco_Ana_Carolina.pdf $>$.

Camargos, J. M. (2013). Causas da não adesão ao exame citopatológico cérvico uterino: uma revisão bibliográfica. Campos Gerais: Universidade Federal de Minas Gerais.

Costa, L. A. \& Goldenberg, P. (2013). Papilomavírus Humano (HPV) entre Jovens: um sinal de alerta. São Paulo: Saúde e Sociedade, $22(1), 249-261$.

Fonseca, A. J., Ferreira, L. C. L. \& Neto, G. B. (2013). Cost-effectiveness of the vaccine against human papillomavirus in the Brazilian Amazon region. São Paulo: Revista da Associação Médica Brasileira, 59(5), 442-451.

Garnelo, L., Souza, A. B. L. \& Silva, C. O. (2017). Regionalização em Saúde no Amazonas: avanços e desafios. Rio de Janeiro: Ciência \& Saúde Coletiva, 22(4), 1225-1234.

Manoel, A. L., Rodrigues, A. B., Piva, E. Z., Warpechowski, Y. P. \& Schuelter-Trevisol, F. (2017). Avaliação do conhecimento sobre o vírus do papiloma humano (HPV) e sua vacinação entre agentes comunitários de saúde na cidade de Tubarão, Santa Catarina, em 2014. Brasília: Revista Epidemiologia e Serviços de Saúde, 26(2), 299-404.

M. Oliveira, M., Andrade, S. S. C. A., Oliveira, P. P. V., Silva, G. A.; Silva, M. M. A. \& Malta, D. C. (2018). Cobertura de exame papanicolaou em mulheres de 25 a 64 anos, segundo a pesquisa nacional de saúde e o sistema de vigilância de fatores de risco e proteção para doenças crônicas por inquérito telefônico, 2013. São Paulo: Revista Brasileira de Epidemiologia, 21, 1-11.

Moura, J. B. L. C. \& Da Silva, G. S. V. (2017). Papanicolau: refletindo sobre o cuidado de enfermagem na atenção básica. Vassouras: Revista Pró-UniverSUS, $8(1), 12-16$.

Murta, E. F. C., Franca, H. G., Carneiro, M. C., Caetano, M. S. S. G., Adad, S. J. \& Souza, M. A. H. (1999). Câncer do colo uterino: correlação com o início da atividade sexual e paridade. São Paulo: Revista Brasileira de Ginecologia e Obstetrícia, 21(9), 555-559.

Nadal, S. R. \& Manzione, C. R. (2006). Vacinas contra o papiloma vírus humano. Rio de Janeiro: Revista Brasileira Coloproctologia, 26(3), 337-340.

Oliveira, H. M., Gonçalves, M. J. F. \& Pires, R. O. M. (2011). Caracterização da Estratégia Saúde da Família no Estado do Amazonas, Brasil: análise da implantação e impacto. Rio de Janeiro: Caderno de Saúde Pública, 27(1), 35-45.

Pinho, M. A. T. (2018). Custo-efetividade da vacina HPV quadrivalente, teste HPV e citologia em meio líquido: revisão integrativa. Fortaleza: Departamento de Enfermagem - Universidade Federal do Ceará.

Pinto, Á. P.; Tulio, S. \& Cruz, O. R. (2002). Co-fatores do HPV na oncogênese cervical. São Paulo: Revista da Associação Médica Brasileira, 48(1), 92-96.

Richart, R.M. (1990). A modified terminology for cervical intraepithelial neoplasia. Philadelphia: Obstetrics \& Gynecology, 75(1), $131-133$.

Silva, P. L. N., Martins, F. G. S., Galvão, A. P. F. C., Souto, S. G. T., Oliveira, R. S. \& Martins, I. M. L. (2021). Sentimentos de pré-adolescentes e adolescentes quanto à vacinação contra o papilomavirus humano. Santana do Parnaíba: Revista Nursing, 24(273), 5529-5534.

Vasconcelos, M. R., Farias, N. S., Aoyama, E. A. \& Souza, R. A. G. (2020). Câncer no colo uterino na menopausa em mulheres acima de 45 anos. Brasília: Revista Brasileira Interdisciplinar de Saúde, 2(1), 88-94.

Viegas, S. M. F., Pereira, P. L. G., Pimenta, A. M., Lanza, F. M., Oliveira, P. P. \& Oliveira, V. C. (2019). Preciso mesmo tomar vacina? Informação e conhecimento de adolescentes sobre as vacinas. Bogotá: Avances em Enfermería, 37(2), 217-226.

Wright, T. C. Jr; Cox, J. T., Massad, L. S., Twiggs, L. B. \& Wilkinson, E. J. (2002). 2001 Consensus guidelines for the management of women with cervical cytological abnormalities. Online: JAMA, 287(16), 2120-2129, 2002. <doi:10.1001/jama.287.16.2120>. 